\title{
The Effect of Trunk Stabilization Exercises Using a Sling on the Balance of Patients with Hemiplegia
}

\author{
JAe Hyo Park, MS, $\mathrm{PT}^{1}$, GaK Hwangbo, PhD, $\mathrm{PT}^{1)^{*}}$ \\ 1) Department of Physical Therapy, College of Rehabilitation Science, Daegu University: 15 Jillyang, \\ Gyeongsan-si, Kyeongbuk 712-714, Republic of Korea
}

\begin{abstract}
Purpose] The purpose of this study was to examine the effects of trunk stabilization exercise using a saing on the balance ability of patients with hemiplegia. [Subjects] Forty patients with hemiplegia resulting from stroke were divided into a sling exercise group ( $\mathrm{SEG}, \mathrm{n}=20$ ) and a mat exercise group (MEG, $\mathrm{n}=20$ ). [Methods] The SEG conducted the trunk stabilization exercise using a sling, and the MEG performed the trunk stabilization exercise on a mat. [Results] The balance ability of both groups significantly improved. Although there were no significant differences between the groups, the SEG showed a greater reduction in the sway area (SA) and the sway length (SL) of the center of the pressure compared to the MEG. [Conclusion] We recommend trunk stabilization exercise using a sling as a clinical intervention to improve the balance ability of patients with hemiplegia.

Key words: Hemiplegia, Trunk stabilization exercise, Sling
\end{abstract}

(This article was submitted Jul. 17, 2013, and was accepted Sep. 1, 2013)

\section{INTRODUCTION}

Hemiplegia is the main symptom of stroke, which results in diverse sensory, motor, perception, recognition, and language problems ${ }^{1}$. Hemiplegia is commonly associated with a decrease in trunk adjustment ability. In particular, it causes a decrease in the activities of the lateral trunk muscles, and an increase in the asymmetry between the left and the right side, as well as paralysis of the trunk muscles. Additional complications are a decrease in the simultaneous contraction of the trunk muscles and a tendency to fall toward the paretic side, triggering problems, such as qualitative degradation of gait $^{2}$. Physical therapy interventions are needed for these motor disorders to enable patients with brain damage to live independent lives.

The trunk muscles are essential for the maintenance of different postures in daily life. Therefore, maintaining the strength and the endurance of the trunk muscles is crucial ${ }^{2}$. Core stability is a kinetic chain activity necessary for the stabilization of the trunk ${ }^{3)}$. It regulates optimal task performance ability, movement, muscle power, and motor ability. Among the intervention methods for trunk stabilization, a sling reduces the burden on the joints and simultaneously contracts the muscles restrained by pain, dynamically and statically, thereby stimulating the nerve roots and reactivating the muscles ${ }^{4}$. Recently, trunk stabilization exercise using a sling has been investigated in a number of studies,

*Corresponding author. Gak Hwangbo (E-mail: hbgak@ daegu.ac.kr)

(C2014 The Society of Physical Therapy Science. Published by IPEC Inc. This is an open-access article distributed under the terms of the Creative Commons Attribution Non-Commercial No Derivatives (by-ncnd) License $<$ http://creativecommons.org/licenses/by-nc-nd/3.0/>. which have reported positive results. Balance and gait are impaired in hemiplegic patients due to loss or reduction of trunk adjustment ability. Therefore, selective trunk adjustment exercise is important, and trunk stabilization exercise is prescribed as an intervention.

Trunk stabilization exercises using a sling are largely reserved for non-hemiplegic people and orthopedic patients. This study investigated the effects of trunk stabilization exercise using a sling on improvements in the balance ability of hemiplegic patients.

\section{SUBJECTS AND METHODS}

The subjects of this study were 40 patients diagnosed with hemiplegia resulting from stroke by a rehabilitation doctor practicing in B Hospital located in Daegu, South Korea. They were randomly and equally assigned to a sling exercise group (SEG: 11 males, 9 female) and a mat exercise group (MEG: 13 males, 7 female). The mean \pm SD age, height, and weight of the SEG was $51.15 \pm 14.81$ years, $163.45 \pm 8.53 \mathrm{~cm}$, and $62.07 \pm 9.79 \mathrm{~kg}$, respectively. Eleven of the patients had right hemiplegia, and nine had left hemiplegia. The onset period was $14.10 \pm 11.40$ months. The mean \pm SD age, height, and weight of the MEG was $48.65 \pm 12.81$ years, $164.10 \pm 8.11 \mathrm{~cm}$, and $63.80 \pm 9.26 \mathrm{~kg}$, respectively. Eight of the patients had right hemiplegia, and 12 had left hemiplegia. The onset period was $12.75 \pm 9.60$ months.

The inclusion criteria were as follows: no visual field defect, no abnormality in the vestibular organs, no orthopedic disease, an unrestricted range of motion, ability to understand and perform the exercise as instructed by the researcher, and a score of 24 or higher on the Mini-Mental State Examination-Korean version. All the subjects under- 
stood the purpose of this study and provided their written informed consent prior to their participation in the study in accordance with the ethical standards of the Declaration of Helsinki.

The SEG contracted the transversus abdominis and raised the trunk in all the exercise positions. In the first exercise of the trunk stabilization exercises using a sling, the patients hooked their heels in the sling and raised their pelvis and maintained it in a raised position for 10 seconds. In the second exercise, the patients hooked one knee in the sling in a side-lying position and raised their pelvis, so that their head, trunk, and lower extremity made a straight line. They maintained this posture for 10 seconds. The same method was performed on the opposite side. In the third exercise, the patients hooked their knees in the sling and raised their trunk and maintained this stance in a prone on elbow position. In the first exercise in the MEG, the patients tilted their pelvis in a hook-lying position (HLP) to the backside and maintained the position for 10 seconds. In the second exercise, they extended their arms toward the front side, raised the scapula in a HLP, and bent the trunk, and maintained the position for 10 seconds. The third exercise involved raising the pelvis and maintaining the position for 10 seconds, taking care to ensure that the lumbar region did not sag. In the fourth exercise, the patients stretched one leg straight in a pelvic elevation position and maintained the position for five seconds, and then adopted the same position on the opposite side ${ }^{5)}$. Both groups conducted their exercises three times per week, 30 minutes each time, and carried out warming-up and cooling-down exercises before and after the exercise. Measurements were collected twice, before and after the intervention, which lasted for 8 weeks.

For the measurement of balance ability, a biofeedback analysis system (AP1153 Biorescue, France), was used to determine the sway area (SA) and the sway length (SL) of the center of the pressure in a static standing position.

The experimental results were statistically analyzed using SPSS 20.0 KO (IBM, IL, USA). After the general characteristics of the subjects were determined, the paired t-test was used to compare the variation in the SA following quiet standing and the variation in the SL following quiet standing between pre- and post- intervention within each group. The significance of the difference between the two groups was investigated using the independent t-test. Statistical significance was accepted for values of $\mathrm{p}<0.05$.

\section{RESULTS}

The SA and the SL of the center of the pressure of the SEG in a standing position had significantly decreased after the intervention $(p<0.05)$. The SA and the SL of the center of the pressure of the MEG in a standing position had also significantly decreased after the intervention $(\mathrm{p}<0.05)$ (Table 1).

The differences in the SA and the SL of the center of the pressure of both groups in a standing position were compared, but no significant difference was found. However, that of the SEG had decreased more than that of the MEG (Table 2).

\section{DISCUSSION}

Pedersen et al. ${ }^{6}$ noted that a trunk stabilization program using a sling significantly improved elite soccer players' posture, balance, kicking speed, and functional strengths of the pelvis and the trunk muscles and concluded that functional muscle strength exercise using a sling was effective at enhancing nerve root adjustment. Park et al. ${ }^{7)}$ reported that the muscle strength of patients with chronic lumbar pain, who conducted a sling exercise for four weeks, significantly

Table 1. Comparison of the COP sway area and length following quiet standing between preand post-intervention of each group (mean $\pm \mathrm{SD}$ )

\begin{tabular}{llcc}
\hline Group & & Experimental group & Control group \\
\hline \multirow{2}{*}{ SA $\left(\text { Unit: } \mathrm{mm}^{2}\right)^{*}$} & Pre-intervention & $120.0 \pm 110.4$ & $118.9 \pm 77.5$ \\
& Post-intervention & $68.6 \pm 56.8$ & $89.3 \pm 65.5$ \\
\multirow{2}{*}{ SL (Unit: cm)* } & Pre-intervention & $32.7 \pm 13.6$ & $30.0 \pm 8.4$ \\
& Post-intervention & $23.0 \pm 11.4$ & $24.3 \pm 6.2$ \\
\hline
\end{tabular}

${ }^{*} \mathrm{p}<0.05$, SA, sway area; SL, sway length.

Table 2. Comparison of the variation in the COP sway area and length following quiet standing between the experimental group and the control group (mean $\pm \mathrm{SD})$

\begin{tabular}{llcc}
\hline Group & & Experimental group & Control group \\
\hline \multirow{3}{*}{ SA (Unit: $\left.\mathrm{mm}^{2}\right)$} & Pre-intervention & $120.0 \pm 110.4$ & $118.9 \pm 77.5$ \\
& Post-intervention & $68.6 \pm 56.8$ & $89.3 \pm 65.5$ \\
& Change between pre- and post- & $-51.5 \pm 61.1$ & $-29.6 \pm 10.1$ \\
& Pre-intervention & $32.7 \pm 13.6$ & $30.0 \pm 8.4$ \\
\multirow{2}{*}{ SL (Unit: cm) } & Post-intervention & $23.0 \pm 11.4$ & $24.3 \pm 6.2$ \\
& Change between pre- and post- & $-9.7 \pm 8.8$ & $-5.6 \pm 4.6$ \\
\hline
\end{tabular}

${ }^{*} \mathrm{p}<0.05, \mathrm{SA}$, sway area; SL, sway length. 
increased in the lumbar region. In a study of lumbar pain patients assigned to trunk stabilization exercise on a mat or the same exercise using a sling, $\mathrm{Kim}^{8)}$ observed that the trunk stabilization exercise using the sling was more effective than the trunk stabilization exercise on the mat for strengthening the muscles of the thoracic and lumbar regions.

In the present study, although the differences were not statistically significant, the SA and SL of the center of the pressure in a static standing position decreased more in the SEG than in the MEG. We attribute the greater decreases in the SA and SL of the center of the pressure of the SEG to conducting the exercise on an unstable base of support. This induces proprioceptive stimuli and activation of the whole muscles in closed kinetic chain exercise. Michael et al. ${ }^{9)}$ proposed that trunk stabilization exercise using a Swiss ball enhanced the strength and balance of the trunk muscle by utilizing muscle tissues that were not usually used, and that the continuous movement of the body was needed to counter the unstable state of the trunk when using the Swiss ball. O'Sullivan et al. ${ }^{10)}$ reported that performing exercise to stabilize the center of the pressure on an unstable base of support stimulated more proprioceptors and motor organs of the cerebrum than exercise on a stable base of support, maximizing the sense of balance and the balance maintaining ability, and effectively enhancing trunk stabilization. The results of the aforementioned studies demonstrate the effectiveness and the importance of exercise on an unstable base of support, including exercise with a sling.
We conclude that trunk stabilization exercise using a sling as a clinical intervention aimed at improving the balance ability of patients with hemiplegia resulting from stroke is useful for patients who need to improve postural adjustment and balance ability.

\section{REFERENCES}

1) Kelley RE, Borazanci AP: Stroke rehabilitation. Neurol Res, 2009, 31: 832-840. [Medline] [CrossRef]

2) Handa N, Yamamoto H, Tani T, et al.: The effect of trunk muscle exercises in patients over 40 years of age with chronic low back pain. J Orthop Sci, 2000, 5: 210-216. [Medline] [CrossRef]

3) Kibler WB, Press J, Sciascia A: The role of core stability in athletic function. Sports Med, 2006, 36: 189-198. [Medline] [CrossRef]

4) Vikne J, Oedegaard A, Laerum E, et al.: A randomized study of new sling exercise treatment vs traditional physiotherapy for patients with chronic whiplash-associated disorders with unsettled compensation claims. J Rehabil Med, 2007, 39: 252-259. [Medline] [CrossRef]

5) Imai A, Kaneoka K, Okubo Y, et al.: Trunk muscle activity during lumbar stabilization exercises on both a stable and unstable surface. J Orthop Sports Phys Ther, 2010, 40: 369-375. [Medline] [CrossRef]

6) Stray-Pedersen JI, Magnussen R, Kuffel E, et al.: Sling exercise training improves balance, kicking velocity and torso stabilization strength in elite soccer players. Med Sci Sports Exerc, 2006, 38: S243. [CrossRef]

7) Park KD, Lee WJ, Park SJ, et al.: The effect of sling-exercise on lumbar back strength stabilization for lumbar hernia operation patients. J Sport Leis Stud, 2005, 25: 339-352.

8) Kim TY: The effects of spinal stability exercise using the sling and mat. Korea Sport Res, 2005, 16: 273-280.

9) Michael J, Andre N: The great body ball handbook, 2nd ed. Blaine: Productive Fitness Products, Inc., 2000, pp 4-11.

10) O'Sullivan PB, Phyty GD, Twomey LT, et al.: Evaluation of specific stabilizing exercise in the treatment of chronic low back pain with radiologic diagnosis of spondylolysis or spondylolisthesis. Spine, 1997, 22: 2959-2967. [Medline] [CrossRef] 